\title{
$\$$ Research Square

\section{Bioprocess optimization of PHB production utilizing agro (sago) waste as a sustainable substrate by the native isolate, Bacillus cereus}

\section{Sriramani Murugan}

Vivekanandha College of Arts and Sciences for Women

\section{Senbgam Duraisamy}

Bharathidasan University

\section{Senthilkumar Balakrishnan}

Haramaya University

Anbarasu Kumarasamy

Bharathidasan University

Amutha Raju ( $\nabla$ jennersclub@yahoo.com )

Periyar University https://orcid.org/0000-0002-2802-363X

\section{Research Article}

Keywords: Sago waste, solid waste disposal, bioplastic, PHB, statistical optimization, FTIR, GC-MS

Posted Date: May 14th, 2021

DOI: https://doi.org/10.21203/rs.3.rs-334519/v1

License: (9) This work is licensed under a Creative Commons Attribution 4.0 International License. Read Full License 


\section{Abstract}

Microbial synthesis of polyhydroxyalkanotes (PHA), the eco-friendly biopolymers are gaining more attention towards restricting the environmental pollution by substituting conventional non-biodegradable petroleum-based plastics. The current study was aimed to economize the polyhydroxybutyrate (PHB) production by optimizing the production media using sago waste, as a substrate and cheapest carbon source, by Bacillus cereus a native isolate obtained from soil where sago waste is disposed in and around Salem District, Tamil Nadu, India. PHB production media was optimized by Placket Burman design and Box Benhen design $\left(\mathrm{pH}\left(\mathrm{X}_{1}=7.07\right)\right.$ temperature $\left(\mathrm{X}_{2}=36.36^{\circ} \mathrm{C}\right)$ sago waste $\left.\left(\mathrm{X}_{3}=19.7 \mathrm{~g} / \mathrm{l}\right)\right)$ and observed a maximum OD values of 2.006 in shake flask culture. The dry weight of PHB extracted under optimized condition was also measured by chloroform extraction method and it was found to be $5.2 \mathrm{~g} / \mathrm{l}$. In addition, Fourier- transform infrared spectroscopy (FTIR), thin layer chromatography (TLC) and Gas Chromatography- Mass Spectrometry (GC-MS) analysis revealed the characteristic features of PHB polymer. Thus this study concludes that the utilization of sage waste for synthesis of value-added products, PHB will not only help in reducing the cost of PHB production process, but also assist to manage the problem associated with solid waste disposal.

\section{Introduction}

Today's modern life style leads to unavoidable usage of petroleum based plastic materials all over the world. The various areas where the usage of plastics have become obligatory are home appliances, computer equipment, components in automobiles, grocery stores, vegetable markets, street vendors, medical field etc. The accumulation of conventional plastic wastes in the environment leads to soil infertility, ground water pollution and irreversible damage to the environment with increased global warming. Thus, these issues of global ecosystem and solid waste management have focused the research towards developing biodegradable plastics with essential physiochemical properties such as polypropylene and polyethylene (Hamieh et al. 2010). The biodegradable polymer, PHB is one of the promising materials of polyhydroxyalkanoate polymer, belonging to the polyester and received more attention due to their microbial origin and biodegradability (Verlinden et al. 2007).

PHBs are intracellular accumulation of carbon and energy by various prokaryotic organisms during surplus carbon is available under other nutrients like nitrogen limitation conditions for bacterial growth. Prokaryotic organisms such as Alcaligenes, Pseudomonas, Bacillus, Rhizobium, Rhodospirillum (Sudesh et al. 2000) are the most commonly studied microorganisms. Several cyanobacterial strains have been screened for PHB production ranging from $0.04-6 \%$ of dry weight of cell under photoautotrophic condition (Nishioka et al. 2001). Amongst these, Bacillus sp. are better choice for industrial scale level of PHB production since, they are fast growing with a group of hydrolytic enzymes and produce copolymers from structurally unrelated carbon sources (Halami 2007). Sharma et al. (2007) demonstrated PHB accumulation in the range of $41.6 \%$ dry weight of cell in nitrogen fixing Nostoc muscorum. Microorganisms rich in poly- $\beta$ - hydroxybutyrate shown their autolysis at slower rate than others with negative for PHB production. So, PHB can act as a carbon and energy reserve source (Kato et al. 1992). 
Bacterial PHB production involves the formation of acetyl-CoA, acetoacetyl-CoA and (R)-3-hydroxybutyrylCoA as intermediate compounds. Similarly, the key enzymes involved in PHB production are acetoacetyl-

CoA- reductase (PhbB) and PHB synthase (PhbC) (Verlinden et al. 2007).

The optimal concentration of media composition and cultural composition also might influence the biomass in terms of optical density (OD) and maintain PHB recovery. Response surface methodology is a statistical tool to screen and optimize the influencing parameters and to study the interactive effect of the variables influencing the cell biomass with enhanced yield of PHB. The aim of the present study is to optimize the PHB production media using sago waste as substrate by the native isolate Bacillus cereus to increase biodegradable PHB yield and to reduce the cost of production process in various scale up studies.

\section{Materials And Methods}

\section{Soil sample collection and screening of bacterial isolates}

Soil of sago wastes were collected from various areas sago industries, Salem District, Tamil Nadu. Soil samples were subjected to serial dilution and followed by spread plating on the nutrient agar plates (Senthilkumar et al. 2014) to screen the bacterial isolates. The discrete colonies based on colony morphology were separately subcultured 3-4 times in order to get pure culture of each isolate. All the pure cultures were maintained in glycerol stock at $-20^{\circ} \mathrm{C}$ until further screening.

\section{Screening of PHB production}

The production of PHB by the bacterial isolates were determined by staining with Sudan black B (slide and plate method).

\section{Slide method}

The bacterial culture was smeared, heat fixed on a slide and immersed in $0.5 \%$ Sudan black B stain with ethylene glycol for $5 \mathrm{~min}$. The slide was air dried several times with xylene and blot dried with absorbent paper. The counter stain ( $0.5 \%$ safranin) was added for $10 \mathrm{sec}$. The slide was washed with tap water and dried and observed under oil immersion by microscope for pink granules.

\section{Plate method}

The test culture was inoculated on the nutrient agar and incubated at $37^{\circ} \mathrm{C}$ for 24 to $48 \mathrm{~h}$. After incubation, the plates were flooded with ethanol solution containing Sudan black B for $20 \mathrm{~min}$ and washed with ethanol for removing excess stain followed by drained off. The plate was observed for blue colonies. PHB producing discrete isolates were subcultured 3-4 times in order to get pure culture of each isolates and stored at $-80{ }^{\circ} \mathrm{C}$ in $5 \%$ glycerol until further characterization. 
The four strains of Sudan Black B positive bacteria (SW 02, 05, 06 and 08) were subjected to analyse their growth in PHB production media. About $1 \%$ inoculum of each bacterial isolate $\left(0.5 \mathrm{OD}_{590}\right)$ was inoculated in flask containing PHB production media, incubated in shaking incubator at $37^{\circ} \mathrm{C}$ for $48 \mathrm{~h}$. For every $5 \mathrm{~h}$, the samples were collected to perform Sudan staining and to measure the bacterial biomass by reading the optical density at $590 \mathrm{~nm}$ using spectrophotometer (made company).

\section{Identification of bacterial isolate}

\section{Phenotypic characterization}

Morphological and biochemical tests including Gram staining, motility, oxidase, catalase, and IMViC (Indole, Methyl red, Vogues-Proskauer, Citrate) were performed (Senthilkumar et al. 2014).

\section{Genotypic characterization}

Genomic DNA extraction was performed from the screened bacterial culture using CTAB-DNA extraction method (Sambrook et al. 1989) and confirmed in 1\% agarose gel electrophoresis. Polymerase Chain Reaction (PCR) was performed for $16 \mathrm{~S}$ rRNA gene amplification using template genomic DNA, the primers (27F AGAGTTTGATCMTGGCTCAG; 1492R TACGGYTACCTTGTTACGACTT) and Taq Master Mix (Taq DNA polymerase is supplied in 2XTaq buffer; $0.4 \mathrm{mM}$ dNTPs; $3.2 \mathrm{mM} \mathrm{MgCl}_{2}$ and $0.02 \%$ bromophenol blue). $16 \mathrm{~S}$ rRNA was amplified up to 30 cycles following denaturation $\left(94^{\circ} \mathrm{C}\right.$ for $\left.3 \mathrm{~min}\right)$, annealing $\left(50^{\circ} \mathrm{C}\right.$ for $60 \mathrm{sec}$ ), extension ( $72^{\circ} \mathrm{C}$ for $10 \mathrm{~min}$ ). Further, PCR product was purified using Montage PCR Clean up kit (Millipore) after confirmed in 1.2\% agarose gel. The purified amplified product was submitted for sequencing the $16 \mathrm{~S}$ rRNA gene.

The 16S rRNA sequences were subjected to BLAST N analysis using NCBI blast similarity search tool. The phylogenetic analysis of query sequence with closely related sequence of blast results was performed followed by multiple sequence alignment. The program MUSCLE 3.7 was used for multiple aligning of sequences (Edgar 2004). The resulting aligned sequences were cured using the program $G$ blocks $0.91 \mathrm{~b}$. This $\mathrm{G}$ blocks eliminates poorly aligned positions and divergent regions (removes alignment noise) (Talavera and Castresana 2007). Finally, the program PhyML 3.0 aLRT was used for phylogeny analysis and HKY85 as substitution model. PhyML was shown to be at least as accurate as other existing phylogeny programs using simulated data, while being one order of magnitude faster. PhyML was shown to be at least as accurate as other existing phylogeny programs using simulated data, while being one order of magnitude faster. The program Tree Dyn 198.3 was used for tree rendering (Dereeper et al. 2008).

\section{Statistical optimization of PHB production media}

\section{Screening the significant variables using PBD}

This study was designed at screening the important variables influencing the PHB production. Totally 9 variables including medium components (sago waste (thippi), peptone, $\mathrm{Na}_{2} \mathrm{HPO}_{4}, \mathrm{KH}_{2} \mathrm{PO}_{4}, \mathrm{CaCl}_{2}, \mathrm{MgSO}_{4}$ ) 
and cultural conditions (temperature, incubation period and $\mathrm{pH}$ ) were chosen. The experimental design with low level $(-1)$ and high level $(+1)$ is given in Table 1 and 2 . The effect of individual variables on PHB production was calculated by first order polynomial equation (1) as given below:

$\mathrm{Y}=\beta_{0}+\Sigma \beta_{\mathrm{i}} X_{\mathrm{i}}$

Where, $Y$ is the response (PHB production), $\beta_{0}$ is the model intercept, $\beta_{i}$ is variable estimates and $X_{i}$ are independent variable. The variable whose confidence levels were higher than $95 \%$ were considered as the most significant factors that influences PHB production.

\section{Optimization by BBD}

Response surface methodology consists of an empirical technique used for evaluation of relationship between cluster of controlled experimental factors and measured response. In this aspect, BBD was adopted for determining the optimum level of significant variables for PHB production. The significant variables involved in this study were as follows: $\mathrm{pH}$, temperature and sago waste). The remaining components described in Plackett-Burman design were maintained at central value throughout the experiment. The full experimental design with regard to their actual values is provided in Table 3.

The data obtained from BBD were analysed by analysis of variance (ANOVA). The experimental values were fitted in second order polynomial equation (2):

$Y=\beta_{0}+\beta_{1} X_{1}+\beta_{0} X_{2}+\beta_{0} X_{3}+\beta_{11} X_{1}^{2}+\beta_{22} X_{2}^{2}+\beta_{33} X_{32}+\beta_{12} X_{1} X_{2}+\beta_{13} X_{1} X_{2}+\beta_{23} X_{2} X_{3}$

Where $Y$ is the measured response, $\beta_{0}$ is the intercept term, $\beta_{1}, \beta_{2}, \beta_{3}$ are liner coefficient, $\beta_{11}, \beta_{22}$, $\beta_{33}$ are quadratic coefficient, $\beta_{12}, \beta_{13}, \beta_{23}$ are interaction coefficient and $X_{1}, X_{2}, X_{3}$ are coded independent variables.

The statistical software Minitab version 15 (Minitab Ltd., Coventry CV3 2TE, UK) was used for regression and graphical analysis of the data obtained. The significance of the model equation and model terms were determined by F-test. The quality of fit of the second polynomial model equation was expressed by $R^{2}$ (coefficient determination) and adjusted $R^{2}$. The fitted equation was expressed as 3-D surface plots to study the relationship between the variables used in this design. Various combinations of optimized variables which gave maximum yield of PHB was tested experimentally to check the validity of the model.

\section{Biomass determinationand PHB quantification}

To determine the biomass of PHB producer, the culture was grown in optimized production media for different incubation period such as $12,24,36,48,60,72 \mathrm{~h}$ and the culture pellet was obtained by centrifuging at $8000 \mathrm{rpm}$ for $15 \mathrm{~min}$. Then it was dried in an oven at $60^{\circ} \mathrm{C}$ to measure the dry weight Mostafa et al. (2020). 
The PHB yield was quantified by following the method of Rawate and Mavinkurve (2002) with minor modifications. Briefly, the culture pellet obtained at different incubation time was treated with $10 \mathrm{ml}$ of sodium hypochlorite. After $2 \mathrm{~h}$ incubation the mixture was centrifuged at $5000 \mathrm{rpm}$ for $15 \mathrm{~min}$ and the pellet was washed separately with distilled water, acetone, methanol. Finally, the pellet was dissolved in 5 $\mathrm{ml}$ of boiled chloroform and was allowed for evaporation by keeping the solution on sterile glass tray at $4^{\circ} \mathrm{C}$ to measure the dry weight of the extracted PHB. The biomass and the extracted PHB was expressed in terms of $\mathrm{g} / \mathrm{l}$. All the experiments were run triplicate and mean values with standard deviation were calculated.

\section{Characterization of PHB}

\section{Thin layer chromatography (TLC)}

About $50 \mu$ lextracted sample was loaded on the TLC plate and allowed to run in the solvent system consisting of ethyl acetate and benzene (Hi media (1:1) mixture for $40 \mathrm{~min}$. For staining, $50 \mathrm{ml}$ of iodine (Hi media) solution was vapourized in water bath at $100^{\circ} \mathrm{C}$. TLC plate was kept over the beaker containing iodine solution for $10 \mathrm{~min}$ to get saturated with iodine vapour. After 10 min green-black colour spots indicated the presence of PHB. The $R_{f}$ (Retardation factor) value was measured and compared with the standard chart (Rawate and Mavinkurve 2002; Senthilkumar and Prabakaran et al. 2006).

\section{Fourier-transform infrared spectroscopy (FTIR) analysis}

One mg of extracted sample was ground well with $10 \mathrm{mg}$ of spectral pure anhydrous potassium bromide crystals. The powder was made into a pellet for FTIR analysis. The relative intensity of transmitted light energy was measured against the wavelength of absorption on the region $500-4000 \mathrm{~cm}^{-1}$ using JEOL-FT IR-4000 plus double beam spectrometer. FTIR spectra of the samples were measured at ambient conditions.

\section{Gas Chromatography-Mass Spectrometry (GC-MS) analysis}

Extracted PHB was dissolved in chloroform at $100{ }^{\circ} \mathrm{C}$ for $10 \mathrm{~min}$ (John and Keller 1999) and $3 \mu \mathrm{L}$ was injected into a GC-MS instrument (Agilent GC 7890A / MS5975C) with capillary column (Agilent DB5MS; Column Length : $30 \mathrm{~m} / 0.25 \mathrm{~mm}$ internal dia / $0.25 \mathrm{micron}$ film thickness) with a run at $50^{\circ} \mathrm{C}$ for $1 \mathrm{~min}$ and followed by $10^{\circ} \mathrm{C} / \mathrm{min}$ to $300^{\circ} \mathrm{C}$ for $2 \mathrm{~min}$. Mass spectra were recorded and compounds were identified using NIST mass spectral library.

\section{Result}

\section{Screening and identification of potent PHB producer}

A total of 15 bacterial isolates (SW 01-15) were screened from the soil collected from areas where sago waste gets dumbed. Of these 4 isolates (SW 02, 05, 06 and 08) were screened as PHB producer by Sudan black B staining and they were subjected for further study. 


\section{Growth curve analysis}

The inoculated culture broth was incubated at shaking incubator at $37^{\circ} \mathrm{C}$ for $50 \mathrm{~h}$ and broth optical density was measured for every $5 \mathrm{~h}$ at $600 \mathrm{~nm}$. All the bacterial isolates reached their logarithmic phase after $5 \mathrm{~h}$ only and the isolate SW 08 showed prolonged logarithmic phase and reached stationary phase after $20 \mathrm{~h}$ only and all other isolates showed short duration of log phase and after $10 \mathrm{~h}$ of incubation, they reached stationary phase (Fig. 1).

\section{Identification of potent PHB producer}

The potent PHB producing isolate (SW 08) was identified by phenotypic and genotypic characterization. The selected isolate, SW 08 was Gram +ve motile non-spore producing rods. It was positive for catalase, citrate and starch hydrolysis and negative for oxidase. Other physiological features were analysed with reference to Bergey's manual of systemic Bacteriology and the strain was identified as a member under Bacillus. The 16S rRNA sequenced from strain SW 08 was 831 bp long. Their similarity analysis was carried out with other 16S rRNA sequences available at NCBI BLAST program (Fig. 2). The isolate SW-08 was found to be $100 \%$ similarity with Bacillus cereus and the sequence was submitted in NCBI under the accession No. MF 188890.

\section{Statistical response surface methodology (RSM)}

\section{Evaluation of variables affecting PHB production using PBD}

The PBD experiment was conducted in 12 runs to evaluate the effect of the selected 9 variables and 2 unassigned variables. The result of screening experiment is shown in Table 2. The maximum PHB production was observed in $10^{\text {th }}$ run, likewise minimum yield was observed in $4^{\text {th }}$ run. ANOVA was performed for this design and given in Table 3. The Pareto chart explains the order of significance of the variables affecting PHB yield (Fig. 3). Among the 9 variables, $\mathrm{pH}$, temperature and sago waste were found to be most significant variables than all others since they only have positive effect on PHB production. The normal probability plot shows the points close to a diagonal line; so the residuals appear to be normally distributed indicating the model fitness with the experimental results.

The $\mathrm{R}^{2}$ value of this design was 0.989 indicates that $98.95 \%$ of the variability in the response was attributed to the selected independent variables and only $1.05 \%$ variations are not explained by these variables. The adjacent $R^{2}$ (Adj. $\left.R^{2}=0.942\right)$ is also very high indicating the significance of the model. In addition, the $F$ value of the model (20.93) shows their significance level. Moreover, the probability $(P)$ value (0.046) also indicates that the terms of the model are significant (Table 3 ).

\section{Optimization of significant variables using BBD}

The designed experiments conducted in this study were aimed to construct quadratic model consisting of 15 independent trails. The experimental design and their results determined the effect of three independent variables ( $\mathrm{pH}$, temperature and sago waste) is given in Table 4. The regression analysis of 
this BBD indicated that three variables, $\mathrm{pH}$, temperature and sago waste have significant $(P \Downarrow 0.00)$ relationship to PHB production. Moreover, the interaction between $\mathrm{CaCl}_{2}$, sago waste and sago waste, fructose have significant effect on PHB yield, as was shown by the low $P$-value $(P \otimes 0.046),(P \otimes 0.025)$ respectively. ANOVA of this experiment illustrates the $P$-value $(P \otimes 0.00)$ and lack of fit value $(0.168)$ and also proposed that the results data obtained from this experimental design was a good fit with the model (Table 5). The data was fitted to a second order polynomial equation. The response of this study, PHB yield $(Y)$ by $B$. cereus, can be expressed in terms of the following equation (3):

$Y=-20.372+2.8312 X_{1}+0.5589 X_{2}+0.5551 X_{3}-0.18367 X_{1}^{2}-0.006496 X_{2}^{2}-0.013879 X_{3}^{2}-$

$0.009067 X_{1} X_{2}+0.004500 x_{1} x_{3}-0.001133 x_{2} x_{3}$

Where $\mathrm{X}_{1}: \mathrm{pH}, \mathrm{X}_{2}$ : temperature, $\mathrm{X}_{3}$ : sago waste $\mathrm{X}_{1}^{2}: \mathrm{pH}^{*} \mathrm{pH}_{1} \mathrm{X}_{2}^{2}$ : temperature * temperature, $\mathrm{X}_{3}^{2}$ : sago waste * sago waste, $\mathrm{X}_{1} \mathrm{X}_{2}: \mathrm{pH}$ * temperature, $\mathrm{X}_{1} \mathrm{X}_{3}: \mathrm{pH}$ * sago waste, $\mathrm{X}_{2} \mathrm{X}_{3}$ : temperature * sago waste

The correlation coefficient $\left(R^{2}\right)$ obtained from ANOVA was about 0.999 and this is a fraction of overall variation in the experiment of the model, so the model is explaining $99.9 \%$ of the variation in the response. The adjusted $\mathrm{R}^{2}(0.998)$ of this experiment indicates that the model is good.

3-D surface plots were constructed using the response (OD value) on the Z-axis against two independent variables and other variables are at their central levels. Fig. 4a explains the impact of $\mathrm{pH}$ and temperature on PHB production. Increased PHB production was observed when $\mathrm{pH}$ was increased but after reaching the threshold level $(\mathrm{pH} 7)$ production was started to decrease whereas at low temperature less production was observed and at high temperature the PHB production was also increased. Similarly, low and high concentration of sago waste also reduced the PHB production rate and at their middle level, maximum PHB production was observed (Fig 4 b \& )

The optimum level of each variable according to the maximum PHB production was determined by fitting experimental data to equation 2 and level of $\mathrm{pH}\left(\mathrm{X}_{1}=7.07\right)$, temperature $\left(\mathrm{X}_{2}=36^{\circ} \mathrm{C}\right)$ and sago waste $\left(X_{3}=19.7 \mathrm{~g} / \mathrm{l}\right)$ providing a maximum PHB production, $5.2 \mathrm{~g} / \mathrm{l}$ in shake flask culture.

Fermentation under the optimized cultural condition of $\mathrm{pH}(7.07)$ temperature $\left(36^{\circ} \mathrm{C}\right)$ and sago waste $(19.7 \mathrm{~g} / \mathrm{l})$ was performed with maximum production of $5.232 \mathrm{~g} / \mathrm{l}$ (Fig. 5), which was slightly higher than the value given by the model $(5.11 \mathrm{~g} / \mathrm{l})$.

\section{Biomass and PHB quantification}

Under the optimized condition $B$. cereus was cultured and their biomass (dry weight) was measured about $1.0 \mathrm{~g} / \mathrm{l}$ and PHB yield was $0.5 \mathrm{~g} / \mathrm{l}$ at the initial duration of $12 \mathrm{~h}$. During the incubation period between $36-60 \mathrm{~h}$ the biomass was substantially increased, while the maximum quantity of PHB accumulation ( $5.2 \mathrm{~g} / \mathrm{l})$ was observed at $72 \mathrm{~h}$ (Fig.6). 


\section{Characterization of PHB}

Greenish-black band was also observed in TLC plate with Rf value of 0.71 indicated the presence of PHB in the production medium. The FTIR spectrum analysis of PHB revealed the presence of characteristic groups such as inter-molecular $\mathrm{H}$ bond, $\mathrm{H}$ bond, $\mathrm{CH}_{2}$ (methylene), $\mathrm{C}=\mathrm{O}$ (Carbonyl) and $\mathrm{C}-\mathrm{O}$ at $400-4000 \mathrm{~cm}^{-}$

${ }^{1}$ (Fig. 7). The presence of methylene and carbonyl group indicate PHB polymer is produced by $B$. cereus. GC-MS studies showed the PHB component's patterns and confirmed the presence of PHB based on retention peak of Phenol, 2,4-bis (1,1-dimethylethyl),1,2-benzenedicarboxylic acid, bis (4-methylpentyl) ester, hexanedioic acid, bis (2-ethylhexyl) ester, methyl ester, methyl ether 3-hydroxybutyric acid, 2,6,10,14,18,22-tetracosahexaene, 2,6,10,15,19,23-hexamethyl-, (all-E)- (Fig. 8).

\section{Discussion}

PHB is the first and most considered PHA to be studied. This PHB is gaining more importance as biopolymers than petroleum-based plastic because of increasing environmental pollution and its ecofriendly nature. The PHB content and its composition are mainly affected by their producing microbial strain, type of substrate and its concentration and their cultural conditions (Saharan et al. 2014). The high cost of PHB production process can be reduced via improving the fermentation and separation process, using low-cost substrate like agricultural waste-by-products.

According to Muthazhagan and Thangaraj (2014), the carbon sources derived from wastes such as whey, cane molasses and sugar beet molasses were used as substrate for PHB production. They also used mustard cake, one of the low cost, renewable nitrogen source. The cheaply available agro residues can be used for the production of PHB and which could be cost effective and sustainable alternative for petroleum-based plastics (Getachew and Woldesenbet 2016). Senthilkumar and Prabakaran (2006) reported that sago waste is a good carbon source and it was found to increase the PHB production at least expensive process.

The optimal production media could enhance the growth of producing strains in terms of optical density and PHB production and recovery. In this study, sago waste is used as a carbon source for improving the bacterial growth and PHB yield. Moreover, the fermentation media is formulated by adding sago waste as substrate and it was statistically optimized to enhance the PHB production. Various bacterial strains were isolated from soil at a sampling site where sago industrial waste disposed in order to screen bacteria to grow in sago waste added newly formulated media. By Sudan black B staining method, about 4 strains were selected for their ability to produce PHB. Based on the morphological and cultural features, PHB producing strain was selected for further study. Phenotypic and genotypic identification confirms the selected PHB producing strain as Bacillus cereus. The evolutionary relationship of the isolate with selected species of the Bacillaceae family was analysed using Neighbor-joining method. Moreover, it is also proved from constructed phylogenetic tree that strain SW 08 forms a separate group with the closest relatives being $B$. cereus. Many Bacillus sp. have been reported with potential of PHB accumulation in their cytoplasm (Hori et al. 2002; Hikmet et al. 2003; Rohini et al. 2006). Sudan black B staining is the 
most effective and easiest technique to screen the PHB producing strains. Among 15 bacterial isolates 4 were found to be positive for Sudan staining indicating their ability to produce lipid granules which could have the presence of PHB.

RSM is an efficient statistical approach to optimize medium components and cultural conditions for enhanced production of PHB within a limited experimental run. Besides, the interaction between the coded variables which is challenging to be studied by conventional one-factor-at-a-time (OVAT) method. In this study, PHB production media is formulated by adding sago waste, the major waste in Salem District, Tamil Nadu, India, as a carbon source in order to decrease the cost of production media since the raw materials used in production media are expensive. Sabapathy et al. (2017) used rice mill as alternative substrate for the production of PHA and reported that about $2.2 \mathrm{~g} / \mathrm{I}$ of PHA was produced from the optimized media. Likewise, pineapple peel also could be a better and an alternative cheapest carbon source for increasing the PHB yield $(5.55 \mathrm{~g} / \mathrm{l})$ by $B$. drentensis strain BP17 under the statistically optimized condition (Penkhrue et al. 2020). The present study also showed high accumulation of PHB was associated with the growth of bacterial strains and the PHB yield was about $5.2 \mathrm{~g} / \mathrm{l}$ when sago waste was sued as carbon source. These studies revealed that the utilization of agro waste such as rice husk, pineapple peel, molasses, sago waste etc, could be a sustainable substrate for the eco-friendly and economic feasible production of PHB polymer.

The PHB polymer extracted from optimized production media and confirmed their presence by TLC by measuring the $R_{f}$ value (0.71). This is consistent with Kiran et al. (2017) who found the PHB $R_{f}$ value of 0.68 and Senthilkumar and Prabhakaran (2006) reported the $R_{f}$ vale of about 0.71 . The presence of functional groups of PHB polymer are inter -molecular $\mathrm{H}$ bond, $\mathrm{H}$ bond, $\mathrm{CH}_{2}$ (methylene), $\mathrm{C}=\mathrm{O}$ (Carbonyl) and $\mathrm{C}-\mathrm{O}$ bond which have been confirmed by FTIR spectroscopy. Senthilkumar and Prabakaran (2006) stated that carbonyl group $(\mathrm{C}=0)$ is a common group of polymer which confirms the presence of $\mathrm{PHB}$ polymer. It also suggests further perceptions towards the chemical structure of the polymer and its monomeric units (Bhagowati et al. 2015). The functional groups determined in the present study were consistent with other studies (Mostafa et al. 2020; Likitha et al. 2018; Gumel et al. 2012) and confirmed the presence of PHB polymer.

The GC-MS analysis of PHB revealed the presence of various ester and ether compounds including bis (4methylpentyl) ester, hexanedioic acid, bis (2-ethylhexyl) ester, methyl ester, methyl ether 3-hydroxybutyric acid. This report is in line with Cardozo et al. (2016) who confirmed the presence of methyl ester in PHB from Bacillus megaterium via the GC-MS spectrum. The predominant peak corresponding to the tetramer of 3HB (hexadecanoic acid) was noted at 13.639 to $13.88 \mathrm{~min}$, respectively (Bhuwal et al. 2014) and these monomer chains are biodegradable polyester family (Choi and Lee 1997). Similarly, the current study spectrum denoted the presence of hexanedioic acid confirming the presence of PHB as well. Mostafa et al. (2020) also confirmed the presence of butanoic acid 2- amino-4-(methylseleno)-, (s); hexanoic acid, 4-methyl-, methyl ester; and hexanedioic acid, monomethyl ester in PHB using GC-MS spectrum. 


\section{Conclusion}

Solid waste management problems around the globe have deviated the research towards developing biodegradable plastics possessing the similar physiochemical properties of the conventional plastics. Microbial origin plays more preferable and suitable alternative for feasible PHB synthesis. In these regards, this study demonstrated the production of PHB using statistically optimized media towards reducing the cost of production process of bioplastics. The media and PHB production process developed using sago waste as carbon source and a native isolate $B$. cereus isolated from sago waste disposed site to achieve the enhanced accumulation of PHB in B. cereus. Moreover, these developed processes will assist for economic production under fermenter conditions at large-scale-level.

\section{Declarations}

\section{Ethical approval and consent to participate}

Not applicable.

\section{Consent for publications}

Not applicable.

\section{Availability of data and materials}

The present study data are available from the corresponding author on reasonable request.

\section{Competing interests}

The authors declare that they have no competing interests.

\section{Funding}

Received financial assistance from UGC, India (30-434/2018(BSR); UGC, India (F.15-1/2016-17/PDFWM2015-17-TAM-36709/ SA-II); Haramaya University grant (HURG 2017-06-01-08); RUSA, 2.0- Biological Sciences, BDU and DST-PURSE.

\section{Authors Contributions}

SM and AR designed the research concept, methodology, data analysis and interpretation. SM, SD and AR carried out the sample collection and laboratory work. AR supervised the research work. SD and AR wrote the manuscript. SD, SB, AK, and AR critically reviewed and revised the manuscript. All authors read and approved the final manuscript.

\section{References}


Bhagowati, P, Pradhan S, Dash HR, Das S (2015) Production, optimization and characterization of polyhydroxybutyrate, a biodegradable plastic by Bacillus spp. Biosci. Biotech Biochem.79(9): 1454-1463.

Bhuwal AK, Singh G, Aggarwal NK et al. (2014) Poly- $\beta$-hydroxybutyrate production and management of cardboard industry effluent by new Bacillus sp. NA10. Bioresour Bioprocess. 1: 9.

Cardozo JRG, Martínez ALM, Pérez MY, Londoño GAC (2016) Production and characterization of polyhydroxyalkanoates and native microorganisms synthesized from fatty waste. Int J Polym Sci. 2016: 6541718.

Choi Ji, Lee S (1997) Process analysis and economic evaluation for Poly(3-hydroxybutyrate) production by fermentation. Bioprocess Eng. 17: 335-342. https://doi.org/10.1007/s004490050394

Dereeper A, Guignon V, Blanc G, et al. (2008) Phylogeny.fr: robust phylogenetic analysis for the nonspecialist. Nucleic Acids Res. 36: W465-W469.

Edgar RC (2004) MUSCLE: multiple sequence alignment with high accuracy and high throughput. Nucleic Acids Res. 32: 1792-1797.

Getachew A, Woldesenbet F (2016) Production of biodegradable plastic by polyhydroxybutyrate (PHB) accumulating bacteria using low cost agricultural waste material. BMC Res. Notes. 9, 509.

Gumel AM, Annuar MSM, Heidelberg T (2012) Biosynthesis and characterization of polyhydroxyalkanoates copolymers produced by Pseudomonas putida Bet001 isolated from Palm Oil mill effluent. PLoS One.7: e45214.

Halami P (2007) Production of polyhydroxyalkanoate from starch by the native isolate Bacillus cereus 95/98/NT. Nucleic Acids Symp Ser. 41:95-98.

Hamieh A, Olama Z, Holail H (2010) Microbial production of polyhydroxy butyrate, a biodegradable plastic using agro-industrial waste products. Global Adv. Res J Microbiol. 2:054-064.

Hikmet K, Belma A, Zehra NK, Nazime M, Yavuz B (2003) Production of PHB and differentiation of putative mutant strains by SDS-PAGE of total cell protein. Afr J Biotechnol. 2:47-149.

Hori K, Kaneko M, Tanji Y, Xing X, Unnu H (2002) Construction of self-disruptive Bacillus megaterium in response to substrate exhaustion for PHB production. Appl Microbiol Biotechnol. 59 (211-216).

John ME, Keller G (1996) Metabolic pathway engineering in cotton: biosynthesis of polyhydroxybutyrate in fiber cells. Proc Natl Acad Sci. 12;93(23):12768-73.

Kato N, Konishi H, Shimao M, Sakazawa C (1992) Production of 3 hydroxybutyric acid trimer by Bacillus megaterium B-124. J Ferment Bioeng. 73: 246-247. 
Kiran GS, Jackson SA, Priyadharsini S. et al. (2017) Synthesis of Nm-PHB (nanomelanin-polyhydroxy butyrate) nanocomposite film and its protective effect against biofilm-forming multi drug resistant Staphylococcus aureus. Sci Rep. 7: 9167. https://doi.org/10.1038/s41598-017-08816-y.

Likitha RV, Namratha V, Sarada B (2018) Production of PHB from Cupriavidus necator using Calophyllum inophyllum seed oil as carbon source. Int J Life Sci Res. 6: 208-2011.

Mostafa YS, Alrumman SA, Alamri SA et al. (2020) Bioplastic (poly-3-hydroxybutyrate) production by the marine bacterium Pseudodonghicola xiamenensis through date syrup valorization and structural assessment of the biopolymer. Sci Rep. 10: 8815. https://doi.org/10.1038/s41598-020-65858-5

Mostafa YS, Alrumman SA, Otaif KA, Alamri SA, Mostafa MS, Sahlabji T (2020) Production and Characterization of Bioplastic by Polyhydroxybutyrate Accumulating Erythrobacter aquimaris Isolated from Mangrove Rhizosphere. Molecules. 25(1):179. doi:10.3390/molecules25010179.

Muthazhagan K, Thangaraj M (2014) Production and ftir analysis of bio-polymer by bacillus sp isolated from vellar estuary sediment. IJSIT. 3:625-638.

Nishioka M, Nakai K, Miyake M, Asada Y, Taya M (2001) Production of poly-b-hydroxybutyrate by thermophilic cyanobacterium, Synechococcus sp. MA19, under phosphate limitation. Biotechnol Lett. 23: 1095-1099.

Penkhrue W, Jendrossek, D, Khanongnuch C, Pathom-aree W, Aizawa T, Behrens RL et al. (2020) Response surface method for polyhydroxybutyrate (PHB) bioplastic accumulation in Bacillus drentensis BP17 using pineapple peel. PLoS One. 15(3): e0230443.

Rawate T, Mavinkurve S (2002) Characterization of polyhydroxy alkonates-Biodegradable plastics from marine bacteria. Curr Sci. 83: 562-564.

Rohini D, Phadnis S, Rawal SK (2006) Synthesis and characterization of PHB from Bacillus thuringiensis R1. Ind J Biotechnol.5:276-283.

Sabapathy PC, Devaraj S, Parthiban A, Kathirvel P (2017) Bioprocess optimization of PHB homopolymer and copolymer P3 (HB-co-HV) by Acinetobacter junii BP25 utilizing rice mill effluent as sustainable substrate. Environ Technol. 39(11): 1430-1441.doi:10.1080/09593330.2017.1330902

Saharan BS, Grewal A, Kumar P (2014) Biotechnological Production of Polyhydroxyalkanoates : A Review on Trends and Latest Developments. Chinese J Biol. http://dx.doi.org/10.1155/2014/802984.

Sambrook J, Fritsch EF, Maniatis T (1989) Molecular cloning: a laboratory manual. 2nd Ed. New York.

Senthilkumar B, Prabakaran G (2006) Production of PHB (Bio-plastics) using bio - effluent as substrate by Alcaligens eutrophus. Ind J Biotechnol. 5(1): 76-79. 
Senthilkumar B, Zothansanga, Senbagam D, Senthilkumar N, Gurusubramaniam G (2014) Practical Microbiology - A Laboratory Manual, 1st Edition, Panima Publishing Corporation, New Delhi, India. http://dx.doi.org/10.13140/2.1.2667.6163.

Sharma L, Kumar Singh A, Panda B, Mallick N (2007) Process optimization for poly- $\beta$-hydroxybutyrate production in a nitrogen fixing cyanobacterium, Nostoc muscorum using response surface methodology. Bioresour Technol. (5): 987-993.

Sudesh K, Abe H, Doi Y (2000) Synthesis, structure and properties of polyhydroxyalkanoates: biological polyesters. Prog Poly Sci. 25: 1503-1555.

Talavera G, Castresana J (2007) Improvement of phylogenies after removing divergent and ambiguously aligned blocks from protein sequence alignments. Syst Biol. 56(4):564-577.

Verlinden RA, Hill DJ, Kenward MA, Williams CD, Radecka I (2007) Bacterial synthesis of biodegradable polyhydroxyalkanoates. J Appl Microbiol. 102:1437-1449.

\section{Tables}

Table 1 Experimental range and levels of independent variables at two levels used for PHB production by $B$. cereus using PBD

\begin{tabular}{|c|c|c|c|}
\hline \multirow[t]{2}{*}{ Code } & \multirow[t]{2}{*}{ Variables } & \multicolumn{2}{|c|}{ Levels } \\
\hline & & $\begin{array}{c}\text { Low level } \\
(-1)\end{array}$ & $\begin{array}{c}\text { High level } \\
(+1)\end{array}$ \\
\hline $\mathrm{A}$ & Sago waste $(\mathrm{g} / \mathrm{l})$ & 10 & 30 \\
\hline $\mathrm{B}$ & Peptone (g/l) & 0.5 & 2 \\
\hline $\mathrm{C}$ & Na2HPO4 & 2 & 5 \\
\hline $\mathrm{D}$ & $\mathrm{KH}_{2} \mathrm{PO}_{4}(\%)$ & 1 & 2 \\
\hline $\mathrm{E}$ & $\mathrm{CaCl}_{2}(\%)$ & 0.1 & 0.2 \\
\hline $\mathrm{F}$ & $\mathrm{MgSO}_{4}(\%)$ & 0.2 & 1 \\
\hline $\mathrm{G}$ & Temperature $\left({ }^{\circ} \mathrm{C}\right)$ & 25 & 40 \\
\hline $\mathrm{H}$ & Incubation Period (h) & 24 & 72 \\
\hline $\mathrm{I}$ & $\mathrm{pH}$ & 5 & 10 \\
\hline
\end{tabular}

Table 2 Twelve trail Placket Burman experimental design for evaluation of nine independent variables with actual values and observed OD values of B. cereus for PHB production 


\begin{tabular}{|c|c|c|c|c|c|c|c|c|c|c|c|}
\hline Run & A & B & C & D & E & F & G & H & I & Predicted PHB production (g/l) & $\begin{array}{c}\text { Observed value } \\
(\mathbf{g} / \mathbf{l})\end{array}$ \\
\hline 1 & 30 & 0.5 & 5 & 1 & 0.1 & 0.2 & 40 & 72 & 10 & 4.51 & 4.481667 \\
\hline 2 & 30 & 2 & 2 & 2 & 0.1 & 0.2 & 25 & 72 & 10 & 3.86 & 3.888333 \\
\hline 3 & 10 & 2 & 5 & 1 & 0.2 & 0.2 & 25 & 24 & 10 & 3.95 & 3.925 \\
\hline 4 & 30 & 0.5 & 5 & 2 & 0.1 & 1 & 25 & 24 & 5 & 3.82 & 3.795 \\
\hline 5 & 30 & 2 & 2 & 2 & 0.2 & 0.2 & 40 & 24 & 5 & 3.87 & 3.841667 \\
\hline 6 & 30 & 2 & 5 & 1 & 0.2 & 1 & 25 & 72 & 5 & 3.91 & 3.935 \\
\hline 7 & 10 & 2 & 5 & 2 & 0.1 & 1 & 40 & 24 & 10 & 3.98 & 4.005 \\
\hline 8 & 10 & 0.5 & 5 & 2 & 0.2 & 0.2 & 40 & 72 & 5 & 3.85 & 3.878333 \\
\hline 9 & 10 & 0.5 & 2 & 2 & 0.2 & 1 & 25 & 72 & 10 & 4.02 & 3.991667 \\
\hline 10 & 30 & 0.5 & 2 & 1 & 0.2 & 1 & 40 & 24 & 10 & 4.52 & 4.548333 \\
\hline 11 & 10 & 2 & 2 & 1 & 0.1 & 1 & 50 & 72 & 5 & 3.86 & 3.835 \\
\hline 12 & 10 & 0.5 & 2 & 1 & 0.1 & 0.2 & 25 & 24 & 5 & 3.59 & 3.615 \\
\hline
\end{tabular}

Table 3 Statistical analysis of PBD with degree of freedom (DF), coefficients, Students test (t-test), Fishers's function (F test) and corresponding level of significance ( $P$ value) for each independent variables affecting PHB production and analysis of variance

\begin{tabular}{|c|c|c|c|c|c|}
\hline & DF & Coefficients & t-Stat & F value & $P$-value \\
\hline Model & 9 & 3.9783 & 210.57 & 20.93 & $0.000^{*}$ \\
\hline A & 1 & 0.1033 & 5.47 & 20.93 & $0.032^{*}$ \\
\hline B & 1 & -0.0733 & -3.88 & 29.91 & 0.060 \\
\hline C & 1 & 0.0250 & 1.32 & 15.07 & 0.317 \\
\hline D & 1 & -0.0783 & -4.15 & 1.75 & 0.054 \\
\hline E & 1 & 0.0417 & 2.21 & 17.19 & 0.158 \\
\hline F & 1 & 0.0400 & 2.12 & 4.86 & 0.168 \\
\hline G & 1 & 0.1200 & 6.35 & 4.48 & $0.024^{*}$ \\
\hline H & 1 & 0.0233 & 1.24 & 40.34 & 0.342 \\
\hline I & 1 & 0.1617 & 8.56 & 1.53 & $0.013^{*}$ \\
\hline
\end{tabular}

$\mathrm{R}^{2}: 0.9895$ (98.95\%) and adjusted $\mathrm{R}^{2}: 0.9422(94.22 \%)$

Table 4 Box Bhenkin design, showing the response of PHB production as influenced by $\mathrm{pH}\left(\mathrm{X}_{1}\right)$, temperature $\left(\mathrm{X}_{2}\right)$ and sago waste $\left(\mathrm{X}_{3}\right)$ with predicted and observed OD values with residuals 


\begin{tabular}{|c|c|c|c|c|c|c|}
\hline Trails & $\mathbf{X}_{1}$ & $\mathbf{X}_{2}$ & $\mathbf{X}_{3}$ & \multicolumn{2}{|c|}{ OD values } & \multirow{2}{*}{ Residuals } \\
\cline { 5 - 7 } & & & & Experimental & Predicted & \\
\hline 1 & 5 & 25 & 20 & 3.38 & 3.36125 & -0.017625 \\
\hline 2 & 10 & 25 & 20 & 3.09 & 3.10375 & -0.020375 \\
\hline 3 & 5 & 40 & 20 & 4.45 & 4.43625 & 0.020375 \\
\hline 4 & 10 & 40 & 20 & 3.48 & 3.43875 & 0.017625 \\
\hline 5 & 5 & 32.5 & 10 & 3.05 & 3.03500 & -0.011000 \\
\hline 6 & 10 & 32.5 & 10 & 2.17 & 2.18250 & -0.008250 \\
\hline 7 & 5 & 32.5 & 30 & 2.76 & 2.74750 & 0.008250 \\
\hline 8 & 10 & 32.5 & 30 & 2.33 & 2.34500 & 0.011000 \\
\hline 9 & 7.5 & 25 & 10 & 2.98 & 2.95375 & 0.028625 \\
\hline 10 & 7.5 & 40 & 10 & 3.80 & 3.82875 & -0.009375 \\
\hline 11 & 7.5 & 25 & 30 & 3.09 & 3.06125 & 0.009375 \\
\hline 12 & 7.5 & 40 & 30 & 3.57 & 3.59625 & -0.028625 \\
\hline 13 & 7.5 & 32.5 & 20 & 5.15 & 5.11333 & 0.017000 \\
\hline 14 & 7.5 & 32.5 & 20 & 5.09 & 5.11333 & -0.004000 \\
\hline 15 & 7.5 & 32.5 & 20 & 5.10 & 5.11333 & -0.013000 \\
\hline
\end{tabular}

Table 5 Statistical analysis of BBD with degree of freedom (DF), coefficients, Students test (t-test), and corresponding level of significance ( $P$ value) for significant variables influencing PHB production and analysis of variance

\begin{tabular}{|c|c|c|c|c|}
\hline & $\mathrm{DF}$ & Coefficients & t-Stat & $P$-value \\
\hline Intercept & 9 & 5.1133 & 264.84 & 0.000 \\
\hline $\mathrm{X}_{1}$ & 3 & -0.3213 & -27.17 & 0.000 \\
\hline $\mathrm{X}_{2}$ & 3 & 0.3450 & 29.18 & 0.000 \\
\hline $\mathrm{X}_{3}$ & 3 & -0.0312 & -2.64 & 0.046 \\
\hline $\mathrm{X}_{1} \mathrm{X}_{1}$ & 3 & -1.1479 & -65.96 & 0.000 \\
\hline $\mathrm{X}_{2} \mathrm{X}_{2}$ & 3 & -0.3654 & -21.00 & 0.000 \\
\hline $\mathrm{X}_{3} \mathrm{X}_{3}$ & 3 & -1.3879 & -79.75 & 0.000 \\
\hline $\mathrm{X}_{1} \mathrm{X}_{2}$ & 3 & -0.1700 & -10.17 & 0.000 \\
\hline $\mathrm{X}_{1} \mathrm{X}_{3}$ & 3 & 0.1125 & 6.73 & 0.001 \\
\hline $\mathrm{X}_{2} \mathrm{X}_{3}$ & 3 & -0.0850 & -5.08 & 0.004 \\
\hline Lack of fit & 3 & & & \\
\hline Pure error & 2 & & & \\
\hline
\end{tabular}

$\mathrm{R}^{2}: 0.9996$ (99.96\%); adjusted $\mathrm{R}^{2}: 0.98988$ (99.88\%)

Figures 

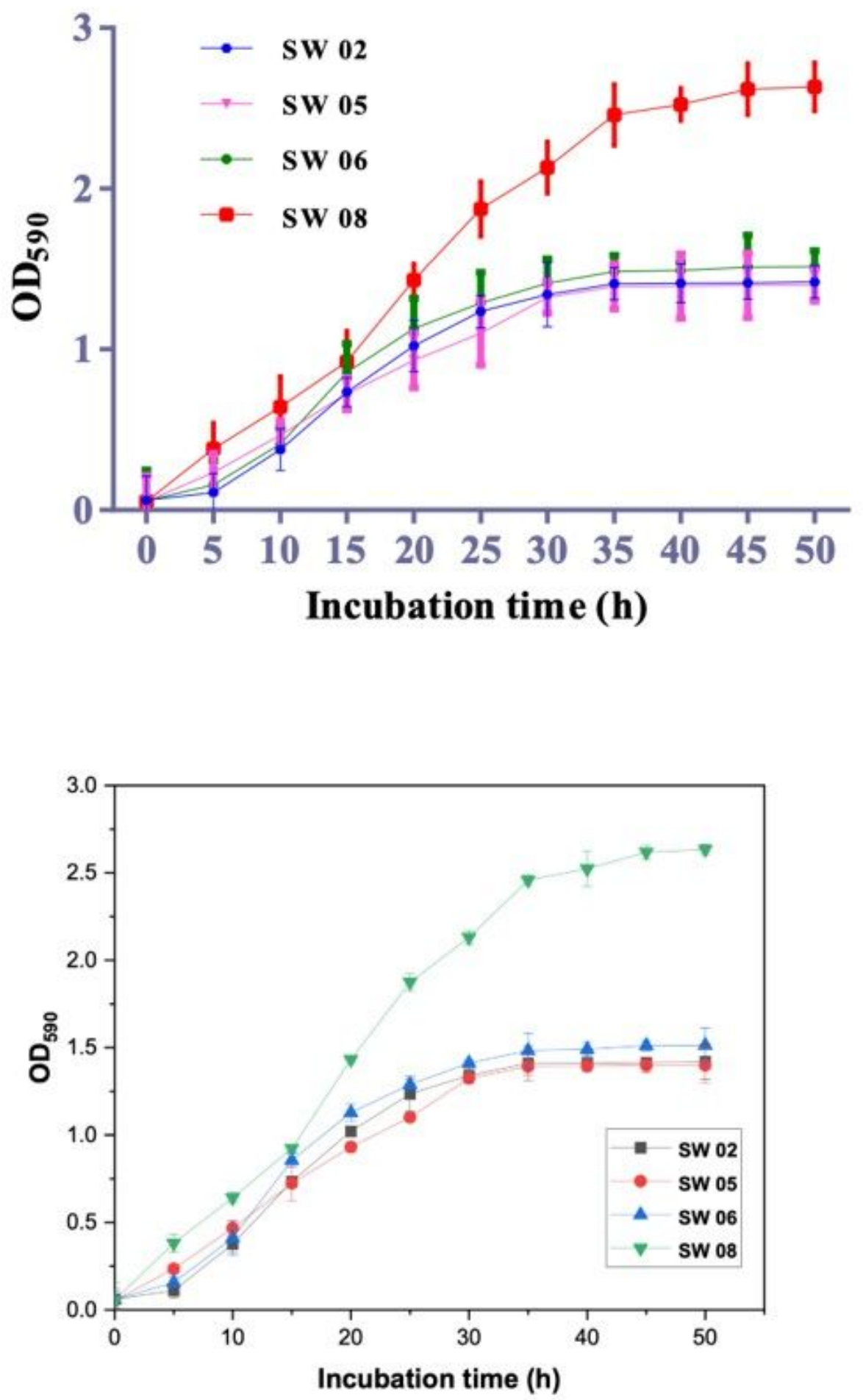

Figure 1

Growth curve showing the OD values of bacterial isolates (SW $02,05,06,08)$ at different time of incubation 


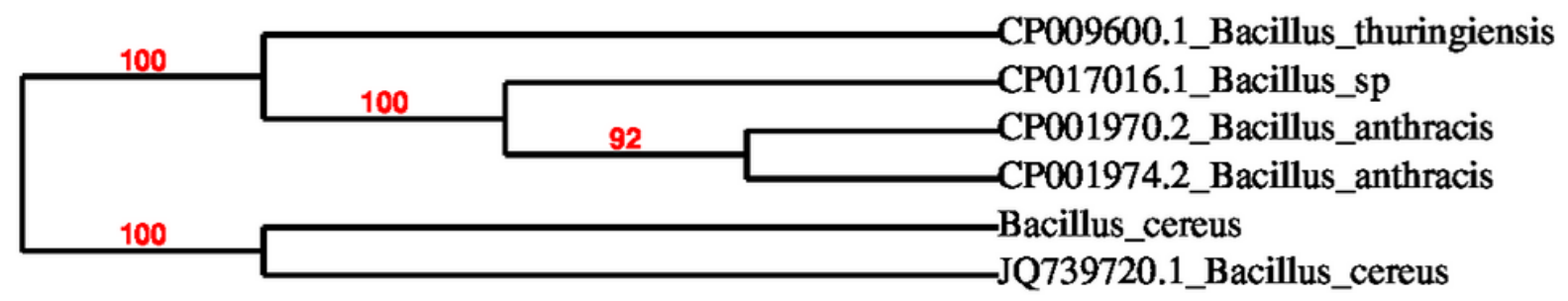

Figure 2

Phylogenetic analysis of PHB producing Bacillus cereus isolate

\section{Pareto Chart of the Standardized Effects (response is PHB production $(g / L), a=0.05$ )}

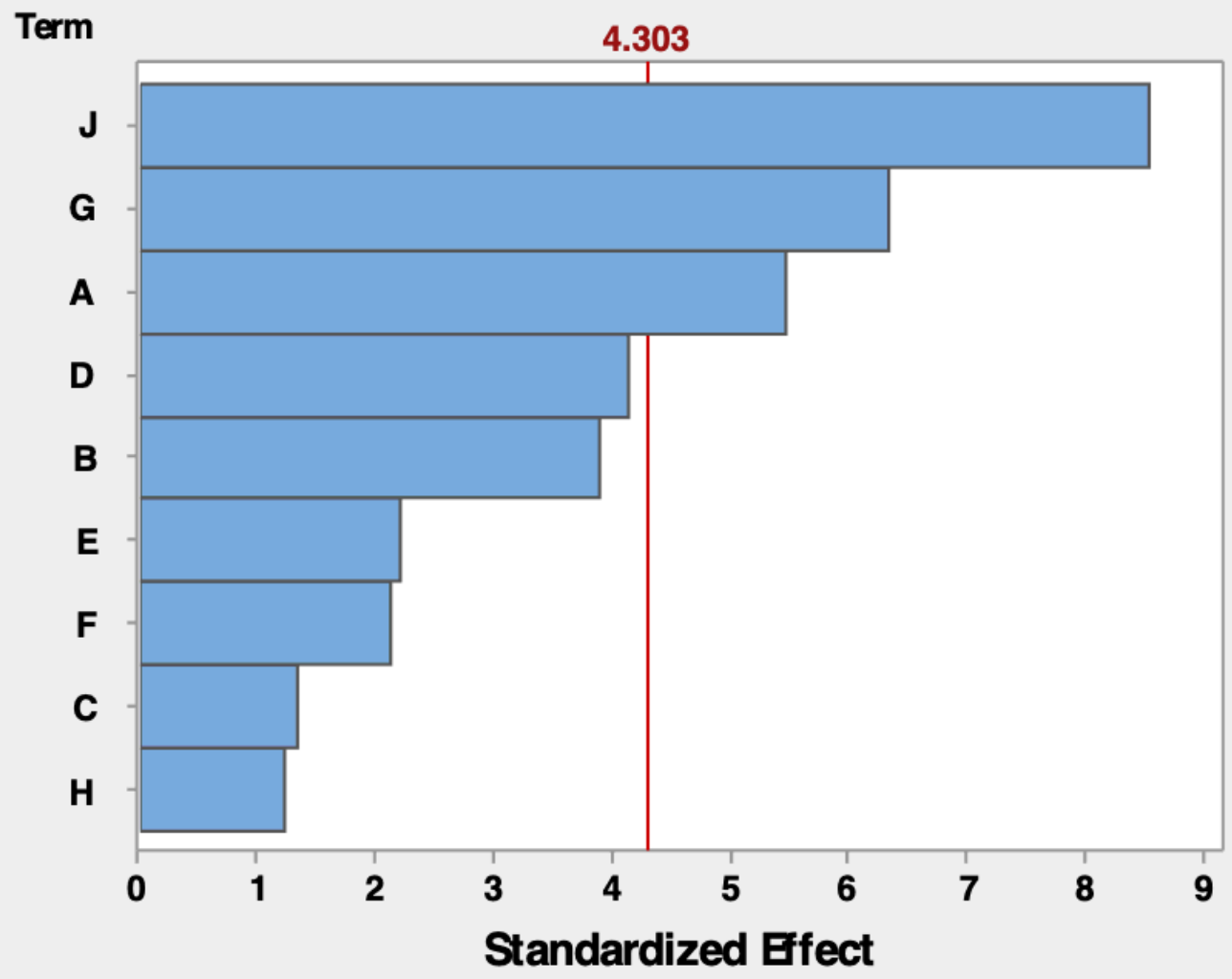

\begin{tabular}{|ll|}
\hline Factor & Name \\
A & Sago waste $(g / L)$ \\
B & Peptone $(g / L)$ \\
C & Na2HPO4 $(g / L)$ \\
D & $\mathrm{KH} 2 \mathrm{PO} 4(\mathrm{~g} / \mathrm{L})$ \\
E & $\mathrm{CaC12}(\mathrm{g} / \mathrm{L})$ \\
F & $\mathrm{MgSO} 4(\mathrm{~g} / \mathrm{L})$ \\
G & Temperature ('C) \\
H & Incubation Period (h) \\
J & pH \\
\hline
\end{tabular}

\section{Figure 3}

Pareto chart explains the order of significance of the independent variables influencing PHB production by increasing mass of $B$. cereus (The red horizontal line indicate the relative frequency of the values) 
Contour Plot of PHB Production ( vs Sago waste ( $g / \mathrm{L}$ ), Temperature (" $\mathrm{C}$ )
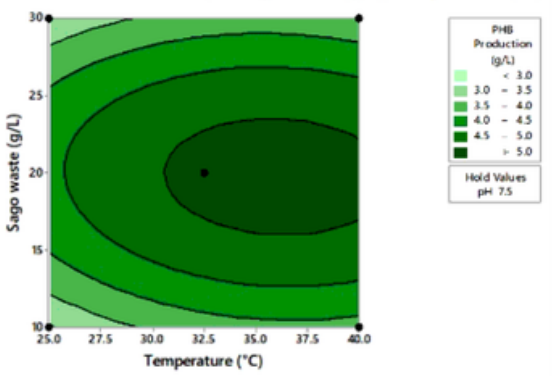

Contour Plot of PHB Production (g/L) vs Sago waste ( $g / \mathrm{L}), \mathrm{pH}$

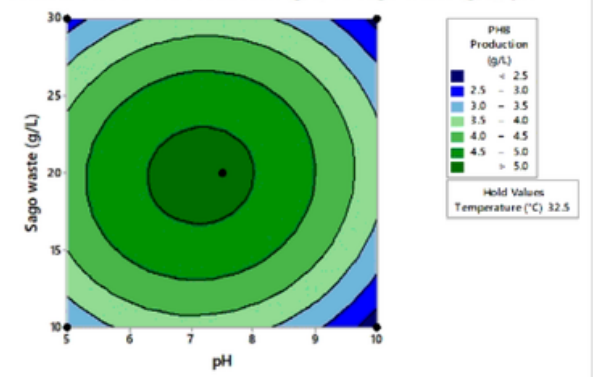

Contour Plot of PHB Production ( $g / L$ ) vs Temperature ( $\left.{ }^{\circ} \mathrm{C}\right)$, pH
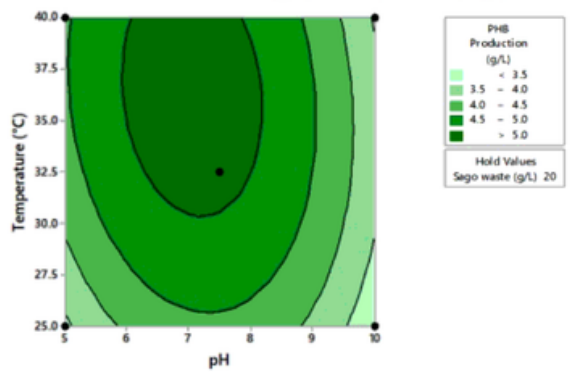

Figure 4

Contour plots showing the interactive effect of $\mathrm{CaCl} 2$, sago waste, fructose for the response optical density of B. cereus

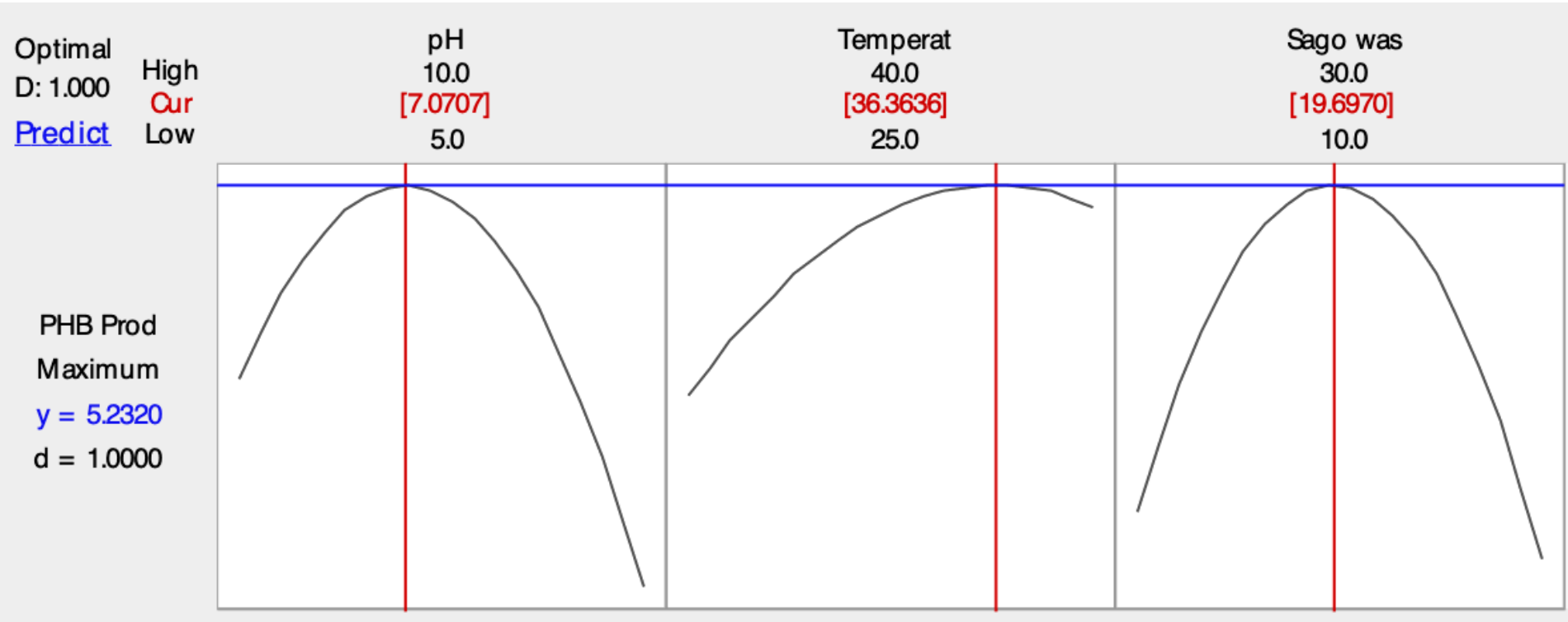

\section{Figure 5}

Optimized level of 3 significant variables by BBD 


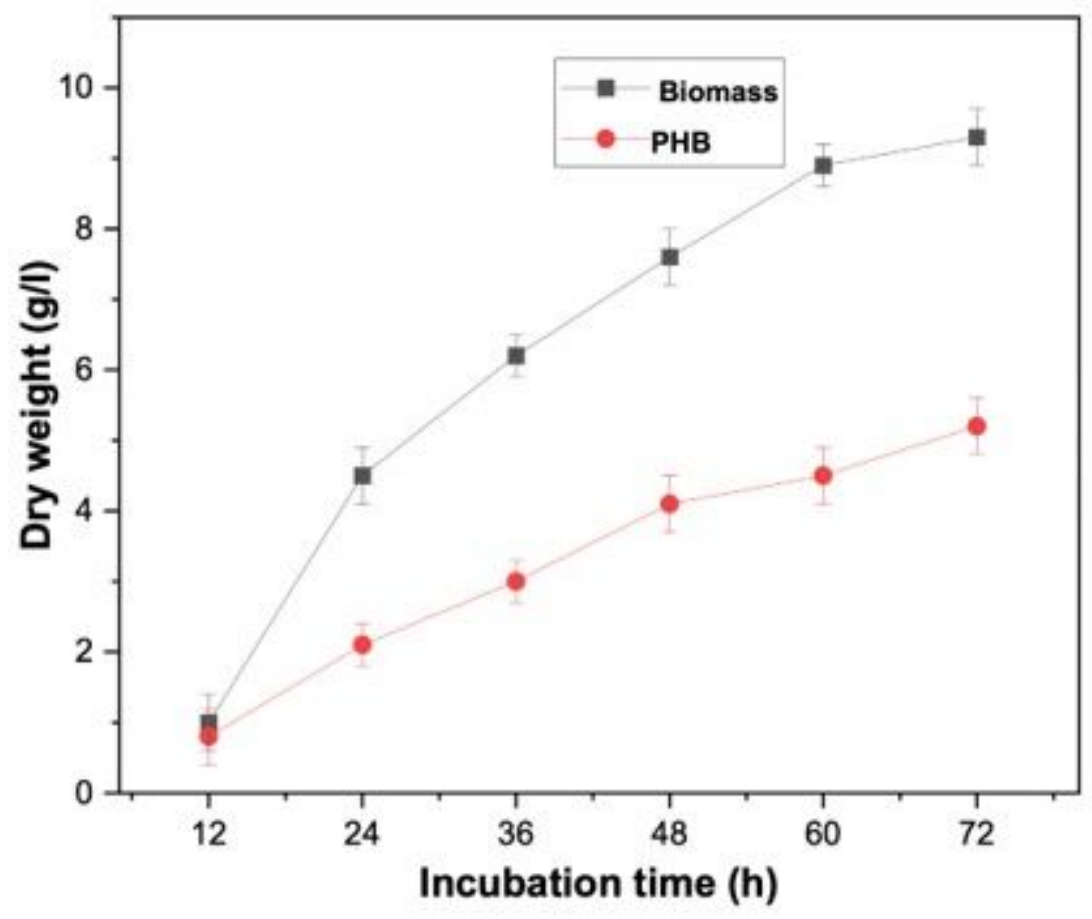

Figure 6

Biomass of B. cereus and yield of PHB from Sago waste at different time points 


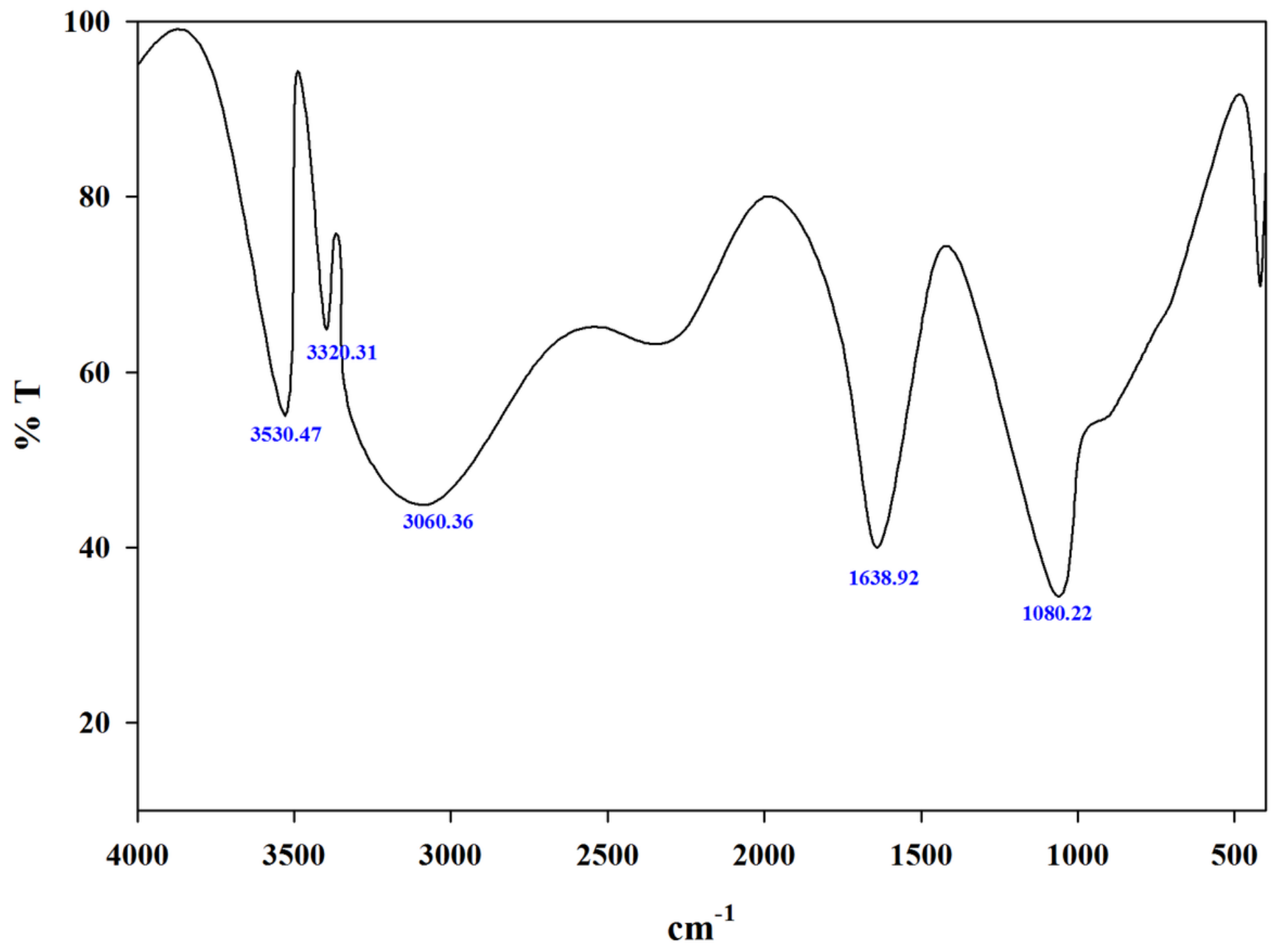

Figure 7

FTIR spectrum of PHB produced using sago waste as substrate 


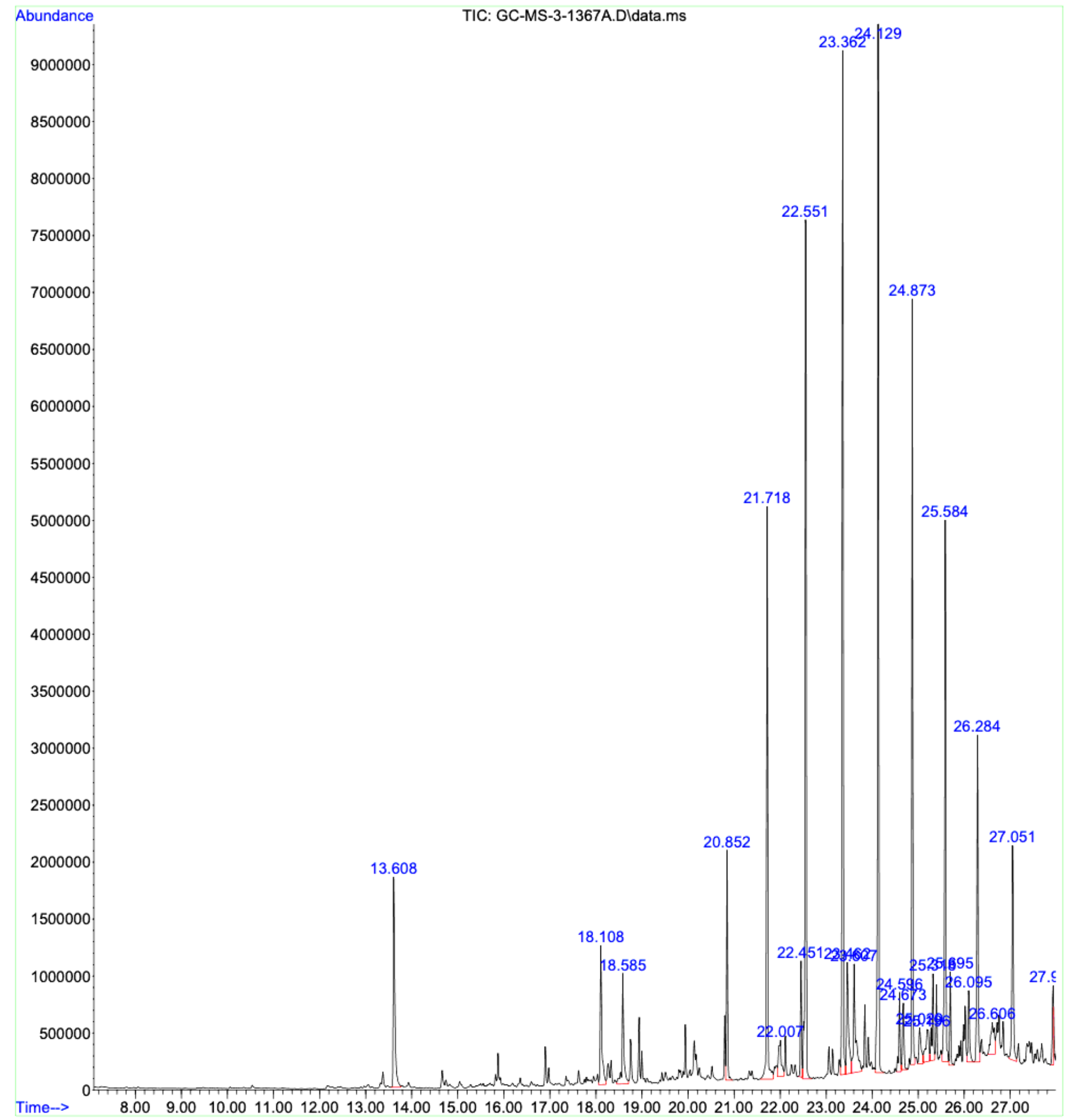

Figure 8

GC-MS Spectra of PHB produced using sago waste as substrate 